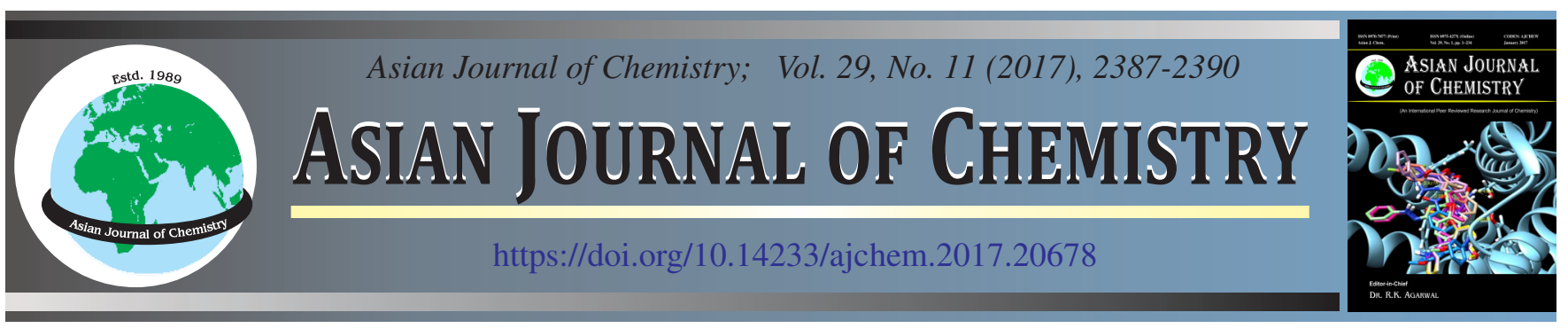

\title{
Synthesis of 3-Substituted Pyrido[1,2-a]pyrimidinethylidenehydrazinylthiozole Derivatives from Pyridine-2-amines
}

\author{
P. Venkateswarlu ${ }^{*}$ and P.K. Dubey
}

Department of Chemistry, Jawaharlal Nehru Technological University Hyderabad, College of Engineering, Kukatpally, Hyderabad-500 085, India *Corresponding author: E-mail: venkatesh6567@gmail.com

Keywords: Thiosemicarbazide, Pyrido[1,2-a]pyrimidine, Dimethylacetylenedicarboxylate, Phenacyl bromide, Chloroacetic acid.

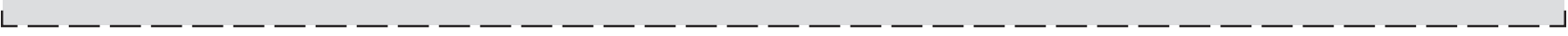

\section{INTRODUCTION}

Acylthiosemicarbazides represent versatile synthons for various syntheses of nitrogen-sulfur heterocycles. The acylthiosemicarbazide moiety provides an opportunity to perform addition-cyclization reactions. Thiosemicarbazones have been used as intermediates for a great variety of heterocyclic products, such as thiazolidinones, thiohydantoins, thioxopyrimidinediones. It is reported that thiazolidinones exhibits antiviral [1], antitumoral agents [2-4], antibacterial [5] and antifungal [6]. We report herein an efficient synthesis of functionalized thiazolidinones derived from 3-acetyl-4H-pyrido[1,2-a]-pyrimidin4-one. In earlier literature, Ignat et al. [7] synthe-sized that thiosemicarbazide condensed with ethyl- $10 \mathrm{H}$-phenothiazine3-carbaldehyde in microwave condition to yield carbothioamide as product. Khalil et al. [8] reported that 3-acetylcoumarin condensed with thiosemicarbazide in ethanol at microwave condition gave 2-(1-(2-oxo-4a,8a-dihydro-2H-chromen-3-yl)ethylidiene)hydrazinecarbothioamide. Awad et al. [9] reported that 2-amino-5-(2-phenyl-1,2,3-triazol-4-yl)-1,3,4-thiadiazole was prepared by the oxidative cyclization of thiosemicarbazone of 4-formyl-1,2,3-triazole with ferric chloride. Kalluraya et al. [10] reported that 4-substituted 3-(3-substituted sydnolydine)4-hydrazonothiazoles have been synthesized under solvent-free conditions by grinding thiosemicarbazone with $\alpha$-bromoketones.

\section{EXPERIMENTAL}

All the reagents used in this work were obtained from commercial suppliers, except ethyl ethoxy methylene aceto- acetate (2). The latter was prepared in the laboratory using a reported procedure [8]. Melting points are uncorrected and were determined using open capillary tubes in sulfuric acid bath. TLC analyses were done on plastic sheets coated with silica gel $\mathrm{G}$ and spotting was done using Iodine/UV lamp. IR spectra were recorded on a Perkin Elmer model 1000 instrument in $\mathrm{KBr}$ pellet. ${ }^{1} \mathrm{H} \mathrm{NMR}$ spectra were recorded in DMSO$d_{6}$ using $400 \mathrm{MHz}$ Varian Gemini spectrometer with TMS as a reference standard. Mass spectra were recorded on Agilent LC-MS mass spectrometer.

Preparation of compound 3 from compounds 1 and 2: A mixture of compound 1 (10 mM), compound 2 (10 mM) and ethanol $(20 \mathrm{~mL})$ was refluxed for $4 \mathrm{~h}$ on a water bath at $\cong$ $100^{\circ} \mathrm{C}$. The reaction was monitored by TLC for disappearance of compound 1. After completion of the reaction, the mixture was poured into ice-cold water $(50 \mathrm{~mL})$ and stirred for $5 \mathrm{~min}$. The separated solid was filtered, washed with water $(2 \times 30$ $\mathrm{mL})$ and dried. The product was recrystallized from methanol to obtain pure compound $\mathbf{3}$.

Compound 3a: Yield $=1.7 \mathrm{~g}(79 \%)$; m.p. $=82-85{ }^{\circ} \mathrm{C}$ (methanol). IR (KBr); 3119-3050 $\mathrm{cm}^{-1}$ of medium intensity $\mathrm{NH}, 1722 \& 1698 \mathrm{~cm}^{-1}(2 \times-\mathrm{C}=\mathrm{O})$. Its ${ }^{1} \mathrm{H}$ NMR (DMSO- $d_{6} /$ TMS) $\delta(\mathrm{ppm}) 1.3\left(\mathrm{t}, 3 \mathrm{H},-\mathrm{CH}_{3}\right), 4.2\left(\mathrm{q}, 2 \mathrm{H},-\mathrm{CH}_{2}\right.$ of ester group), 2.4 (s, $3 \mathrm{H}, \mathrm{CH}_{3}$ of the ester group), 8.1- 8.3 (t, $3 \mathrm{H}, J=$ $6 \mathrm{~Hz}$, thee aryl protons of pyridine ring), $8.5(\mathrm{~s}, 1 \mathrm{H}, \alpha-\mathrm{H}$ to the enamine nitrogen), 9.2 (q, one proton of the pyridine ring). Its LC-MS (HR-MS); $m / z=235.1083,\left(\left[\mathrm{C}_{12} \mathrm{H}_{14} \mathrm{~N}_{2} \mathrm{O}_{3}\right]+\mathrm{H}\right)^{+}$.

Compound 3b: Yield = $1.5 \mathrm{~g}(74 \%)$; m.p. $=105-108{ }^{\circ} \mathrm{C}$ (methanol); IR (KBr): $1724 \mathrm{~cm}^{-1}$ and $1700 \mathrm{~cm}^{-1}$ (two $-\mathrm{C}=\mathrm{O}$ ). ${ }^{1} \mathrm{H}$ NMR (DMSO- $d_{6} / \mathrm{TMS}$ ); $\delta 1.3\left(\mathrm{t}, 3 \mathrm{H}, J=6 \mathrm{~Hz},-\mathrm{CH}_{3}\right), 4.2$ 
(q, $2 \mathrm{H}-\mathrm{CH}_{2}$ of ester group), $2.4\left(\mathrm{~s}, 3 \mathrm{H},-\mathrm{CH}_{3}\right), 7.3$ (s, 1H, Ar$\mathrm{H}), 7.6(\mathrm{q}, 1 \mathrm{H}, \mathrm{J}=6.8 \mathrm{~Hz}, \mathrm{Ar}-\mathrm{H}), 8.1$ (t, 2H, Ar-H, 2 protons of pyridine ring), $8.5(\mathrm{~s}, 1 \mathrm{H}, \alpha-\mathrm{H}$ to the enamine nitrogen); LC-MS: $m / z=314\left[\mathrm{M}^{+}+1\right]$.

Preparation of compound 4 from compound 3: Compound $3(5 \mathrm{mM})$ was added in small lots to hot diphenyl ether at 255 ${ }^{\circ} \mathrm{C}(\mathbf{2 5} \mathrm{mL})$. After completion of addition, the mixture was kept at $255{ }^{\circ} \mathrm{C}$, for about $30 \mathrm{~min}$. After the completion of reaction, as indicated by TLC for disappearance of $\mathbf{3}$, the mixture was cooled to room temperature and poured into $n$ hexane $(50 \mathrm{~mL})$. The separated solid was filtered, washed with $n$-hexane $(2 \times 20 \mathrm{~mL})$ and dried. The crude solid was recrystallized from acetone to obtain pure compound 4 .

4a: Yield $=1.1 \mathrm{~g}(65 \%)$; m.p. $=151-154{ }^{\circ} \mathrm{C}$ (Chloroform). IR (KBr) $1748 \& 1698 \mathrm{~cm}^{-1}\left(-\mathrm{COCH}_{3}\right.$ and $\left.-\mathrm{N}-\mathrm{C}=\mathrm{O}\right)$. The ${ }^{1} \mathrm{H}$ NMR (DMSO- $\left.d_{6} / \mathrm{TMS}\right) \delta(\mathrm{ppm}) 2.4\left(\mathrm{~s}, 3 \mathrm{H},-\mathrm{CH}_{3}\right), 8.2(\mathrm{t}, 3 \mathrm{H}$, aryl thee protons of pyridine ring), $8.6(\mathrm{~s}, 1 \mathrm{H}, \alpha-\mathrm{H}$ to the enamine nitrogen), 9.2 (q, one proton of pyridine ring); ${ }^{13} \mathrm{C}$ NMR (100 MHz, DMSO- $d_{6} / \mathrm{TMS}$ ); showed signals at 31.5 , 110.3, 117.2, 121.0, 139.0, 154.1, 158.1, 193.5; Its LC-MS (HR-MS): $m / z=189.0661,\left(\left[\mathrm{C}_{10} \mathrm{H}_{8} \mathrm{~N}_{2} \mathrm{O}_{2}\right]+\mathrm{H}\right)^{+}$.

Compound 4b; Yield $=1 \mathrm{~g}(62 \%)$; m.p. $=170-174{ }^{\circ} \mathrm{C}$ (chloroform); IR(KBr): 1748 and $1698 \mathrm{~cm}^{-1}$ (two -CO groups; ${ }^{1} \mathrm{H}$ NMR (DMSO-d $\left.d_{6} / \mathrm{TMS}\right): \delta 2.6\left(\mathrm{~s}, 3 \mathrm{H},-\mathrm{CH}_{3}\right), 7.7$ (s, $1 \mathrm{H}$, pyridine proton), $8.40(\mathrm{~s}, 1 \mathrm{H}$, pyridine ring proton), 8.7 (s, $1 \mathrm{H}, \alpha-\mathrm{H}$ to the enamine nitrogen $) ;{ }^{13} \mathrm{C} \mathrm{NMR}(100 \mathrm{MHz}$, DMSO-d $\left.d_{6} / \mathrm{TMS}\right): 31.9,110.3,118.4,122.4,139.0,154.1,158.1$, 192.6; LC-MS: $m / z=268\left[\mathrm{M}^{+}+1\right]$.

Preparation of compound 5 from compound 4: A mixture of compound $4(10 \mathrm{mM})$, thiosemicarbazide $(10 \mathrm{mM})$ ethanol, stirring at room temperature for $4 \mathrm{~h}$. After completion of the reaction, as indicated by the TLC disappearance of compound 4 , the mixture was poured into ice-cold water $(100 \mathrm{~mL})$. The separated solid was filtered, washed with water $(2 \times 30 \mathrm{~mL})$ and dried. The crude product was recrystallized from isopropyl alcohol to obtain pure compound $\mathbf{5}$.

Compound 5a; Yield $=0.9 \mathrm{~g}(60 \%) ;$ m.p. $=180-184{ }^{\circ} \mathrm{C}$ (ethanol) IR (KBr): $3119-3050 \mathrm{~cm}^{-1}$ (medium intensity, $-\mathrm{NH}$ ), $1722 \& 1698 \mathrm{~cm}^{-1}$ (strong, sharp, $\mathrm{C}=\mathrm{O}$ ). ${ }^{1} \mathrm{H}$ NMR (DMSO-d $/$ TMS); $\delta$ (ppm) $2.4\left(\mathrm{~s}, 3 \mathrm{H}, \mathrm{CH}_{3}\right), 7.4-8.8(\mathrm{t}, 3 \mathrm{H}$, thee aryl protons of pyridine ring), $9.3(\mathrm{~s}, 1 \mathrm{H}, \alpha-\mathrm{H}$ to the enamine nitrogen), 10.2 (s, $1 \mathrm{H}-\mathrm{NH}) .{ }^{13} \mathrm{C}$ NMR (100 MHz, DMSO- $d_{6} /$ TMS) 16.1, 113.6, 117.4, 126.1, 127.5, 138.2, 147.2, 151.1, 153.9, 155.9, 178.1. LC-MS: $m / z=262\left[\mathrm{M}^{+}+1\right]$.

Compound 5b: (i.e., 7, $\mathrm{X}=\mathrm{Br})$; Yield $=1 \mathrm{~g}(61 \%)$; m.p. $>250{ }^{\circ} \mathrm{C}$ (acetic acid); IR (KBr): 1730 and $1668 \mathrm{~cm}^{-1}$ (strong, sharp, -CO-); ${ }^{1} \mathrm{H}$ NMR (400 MHz, DMSO- $\left.d_{6} / \mathrm{TMS}\right) ; \delta$ (ppm) $2.1\left(\mathrm{~s}, 3 \mathrm{H},-\mathrm{CH}_{3}\right), 3.4$ (s, 3H, $\left.-\mathrm{CH}_{3}\right), 4.1$ (s, $\left.3 \mathrm{H},-\mathrm{CH}_{3}\right), 7.1-8.0$ $(\mathrm{m}, 3 \mathrm{H}$, pyridine protons), $8.5(\mathrm{~s}, 1 \mathrm{H}, \alpha-\mathrm{H}$ to the enamine nitrogen), 9.1 (s, 1H, -NH). LC-MS: $m / z=342\left[\mathrm{M}^{+}+1\right]$.

Preparation of compound 6 from compound 5: A mixture of compound $5(10 \mathrm{mM})$, phenacyl bromide $(10 \mathrm{mM})$ acetic acid, sodium acetate was refluxed for $4 \mathrm{~h}$. After completion of the reaction, as indicated by the TLC disappearance of compound $\mathbf{5}$, the mixture was poured into ice-cold water $(100 \mathrm{~mL})$. The separated solid was filtered, washed with water $(2 \times 30 \mathrm{~mL})$ and dried. The crude product was recrystallized from isopropyl alcohol to obtain pure compound $\mathbf{6}$.
Compound 6a (i.e., 6, $\mathrm{X}=\mathrm{H})$; Yield = $1.5 \mathrm{~g}(67 \%)$; m.p. $>250{ }^{\circ} \mathrm{C}$ (Isopropyl alcohol). IR 3110-3040 $\mathrm{cm}^{-1}-\mathrm{NH}, 1747$ $\mathrm{cm}^{-1}$ (strong, sharp, $-\mathrm{C}=\mathrm{O}$ ). ${ }^{1} \mathrm{H}$ NMR (DMSO- $\left.d_{6} / \mathrm{TMS}\right) \delta(\mathrm{ppm})$ $2.4\left(\mathrm{~s}, 3 \mathrm{H}, \mathrm{CH}_{3}\right), 7.1-8.8(\mathrm{t}, 3 \mathrm{H}, J=6 \mathrm{~Hz}$, three protons of the pyridine ring), 9.2 (s, $1 \mathrm{H}, \alpha-\mathrm{H}$ to the enamine nitrogen), 10.1 (s, 1H, NH). LC-MS: $m / z=396\left[\mathrm{M}^{++}+1\right]$.

Compound 6b (i.e., 6, $\mathrm{X}=\mathrm{Br}$ ); Yield = $1.4 \mathrm{~g}(66 \%)$; m.p. $>250{ }^{\circ} \mathrm{C}$ (isopropyl alcohol); IR (KBr): 1740 and $1680 \mathrm{~cm}^{-1}$ (strong, sharp, -C=O); ${ }^{1} \mathrm{H}$ NMR (400 MHz, DMSO- $d_{6} / \mathrm{TMS}$ ); $\delta(\mathrm{ppm}) 2$ (s, 3H, $\left.\mathrm{CH}_{3}\right), 7.1-8.8(\mathrm{~m}, 9 \mathrm{H}$, Aryl protons \& pyridine protons), 9.2 (s, 1H, -NH). LC-MS: $m / z=475\left[\mathrm{M}^{++}+1\right]$.

Preparation of compound 7 from compound 5: A mixture of compound $\mathbf{5}(10 \mathrm{mM})$, dimethylacetylene dicarboxylate (DMAD) $(10 \mathrm{mM})$ in ethanol was refluxed for $3 \mathrm{~h}$. After completion of the reaction, as indicated by the TLC disappearance of compound $\mathbf{5}$, the mixture was poured into icecold water $(60 \mathrm{~mL})$. The separated solid was filtered, washed with water $(2 \times 30 \mathrm{~mL})$ and dried. The crude product was recrystallized from isopropyl alcohol to obtain pure compound 7.

Compound 7a (i.e., 7, $\mathrm{X}=\mathrm{H})$; Yield = $1.5 \mathrm{~g}(67 \%)$; m.p. $>250{ }^{\circ} \mathrm{C}$ (acetic acid). IR ( $\left.\mathrm{KBr}\right) 3110-3040 \mathrm{~cm}^{-1}-\mathrm{NH}, 1743$ \& $1695 \mathrm{~cm}^{-1}\left(-\mathrm{COCH}_{3}\right.$ and $\left.-\mathrm{N}-\mathrm{C}=\mathrm{O}\right) .{ }^{1} \mathrm{H}$ NMR (DMSO- $d_{6} /$ TMS) $\delta$ (ppm) 2.4 (s, 3H, methyl), 4.1 (s, 3H, $\left.\mathrm{CH}_{3}\right), 4.3$ (s, $1 \mathrm{H}$, methine proton), 7.1-8.9 $(\mathrm{t}, 4 \mathrm{H}$, four protons of the pyridine ring), $9.2(\mathrm{~s}, 1 \mathrm{H}, \alpha-\mathrm{H}$ to the enamine nitrogen), $10.3(\mathrm{~s}, 1 \mathrm{H}$, $\mathrm{NH})$. Its LC-MS $m / z=359\left[\mathrm{M}^{++}+1\right]$.

Compound 7b (i.e., 7, $\mathrm{X}=\mathrm{Br}$ ); Yield $=1.2 \mathrm{~g}(65 \%)$; m.p. $>250{ }^{\circ} \mathrm{C}$ (acetic acid); IR (KBr): 1740 and $1680 \mathrm{~cm}^{-1}$ (strong, sharp, -CO-); ${ }^{1} \mathrm{H}$ NMR (400 MHz, DMSO- $\left.d_{6} / \mathrm{TMS}\right) ; \delta$ (ppm) $2\left(\mathrm{~s}, 3 \mathrm{H},-\mathrm{CH}_{3}\right), 3.2\left(\mathrm{~s}, 3 \mathrm{H},-\mathrm{CH}_{3}\right), 4\left(\mathrm{~s}, 3 \mathrm{H},-\mathrm{CH}_{3}\right), 7.1-8.1(\mathrm{~m}$, $3 \mathrm{H}$, pyridine protons), 8.6 ( $\mathrm{s}, 1 \mathrm{H}, \alpha-\mathrm{H}$ to the enamine nitrogen), 9.2 (s, 1H, -NH). LC-MS: $m / z=439\left[\mathrm{M}^{++}+1\right]$.

Preparation of compound 8 from compound 5: A mixture of compound $\mathbf{5}(10 \mathrm{mM})$, chloroacetic acid $(10 \mathrm{mM})$, in 1,4-dioxane a few drops of triethylamine was refluxed for $5 \mathrm{~h}$. After completion of the reaction, as indicated by the TLC disappearance of compound $\mathbf{5}$, the mixture was poured into ice-cold water $(150 \mathrm{~mL})$. The separated solid was filtered, washed with water $(2 \times 40 \mathrm{~mL})$ and dried. The crude product was recrystallized from acetic acid to obtain pure compound $\mathbf{8}$.

Compound 8a (i.e., 8, X=H); Yield = 1.6 g (67 \%); m.p. $>250{ }^{\circ} \mathrm{C}$ (acetic acid). $3110-3040 \mathrm{~cm}^{-1}(-\mathrm{NH}), 1743 \& 1695$ $\mathrm{cm}^{-1}\left(-\mathrm{COCH}_{3}\right.$ and $\left.-\mathrm{N}-\mathrm{C}=\mathrm{O}\right) .{ }^{1} \mathrm{H}$ NMR (DMSO- $\left.d_{6} / \mathrm{TMS}\right) \delta$ (ppm) 2.3 (s, 3H, $\left.\mathrm{CH}_{3}\right), 4.1$ (s, 3H, $\left.\mathrm{CH}_{3}\right), 4.3$ (s, $\left.1 \mathrm{H}, \mathrm{CH}_{2}\right)$, 7.1-8.9 (t, $4 \mathrm{H}$, four protons of the pyridine ring), $9.2(\mathrm{~s}, 1 \mathrm{H}$, $\alpha-\mathrm{H}$ to the enamine nitrogen), 10.3 (s, $1 \mathrm{H}, \mathrm{NH})$. LC-MS: $\mathrm{m} / z$ $=359\left[\mathrm{M}^{++}+1\right]$.

Compound 8b (i.e., 8, X=Br); Yield = $1.4 \mathrm{~g}(66 \%)$; m.p. $>250{ }^{\circ} \mathrm{C}$ (acetic acid); IR (KBr): 1740 and $1680 \mathrm{~cm}^{-1}(2 \times-$ CO-); ${ }^{1} \mathrm{H}$ NMR (400 MHz, DMSO- $d_{6} / \mathrm{TMS}$ ); $\delta$ (ppm) 2.1 (s, $\left.3 \mathrm{H},-\mathrm{CH}_{3}\right), 4\left(\mathrm{~s}, 3 \mathrm{H},-\mathrm{CH}_{3}\right), 7.1-8.1$ ( $\mathrm{m}, 3 \mathrm{H}$, pyridine protons), $8.6(\mathrm{~s}, 1 \mathrm{H}, \alpha-\mathrm{H}$ to the enamine nitrogen), $9.1(\mathrm{~s}, 1 \mathrm{H},-\mathrm{NH})$. LC-MS: $m / z=381\left[\mathrm{M}^{++}+1\right]$.

\section{RESULTS AND DISCUSSION}

Commercially available 2-aminopyridine 1a (i.e., 1, X=H) was condensed with ethyl ethoxymethyleneacetoacetate (2) in ethanol under refluxing conditions for $4 \mathrm{~h}$ giving a product 
which has been characterized as ( $Z$ )-ethyl 3-oxo-2-((pyridin2-ylamino)methylene)butanoate $\mathbf{3 a}($ i.e., $\mathbf{3}, \mathrm{X}=\mathrm{H})$ on the basis of its spectral data. Similar reaction of $\mathbf{1 b}$ (i.e., $\mathbf{1}, \mathrm{X}=\mathrm{Br}$ ) with $\mathbf{2}$ resulted in the formation of $\mathbf{3 b}$ (i.e., $\mathbf{3}, \mathrm{X}=\mathrm{Br}$ ), whose structure has been established on the basis of its spectral data. On thermal cyclization in diphenyl ether for $30 \mathrm{~min}$ at $255^{\circ} \mathrm{C}$, 3a gave a product which has been characterized as 3-acetyl- $4 H$-pyrido[1, 2a] pyrimidin-4-one $4 \mathbf{a}$ (i.e., $4, \mathrm{X}=\mathrm{H}$ ) on the basis of its spectral data. Similar reaction of $\mathbf{3} \mathbf{b}$ (i.e., $\mathbf{3}, \mathrm{X}=\mathrm{Br}$ ) gave the product 4b (i.e., 4, $\mathrm{X}=\mathrm{Br}$ ), whose structure has been established on the basis of its spectral data.

Formation of compound $\mathbf{4}$ from compound $\mathbf{3}$ probably occurs by a mechanism shown in Scheme-I. The enamine nitrogen loses its proton which facilitates the ring nitrogen to donate its electrons to the carbonyl carbon which is attached to the ester group. This is further stabilized by the elimination of ester in the form of ethanol leading to the formation of the product (Scheme-II).

Thiosemicarbazide treated with 3-acetyl-4H-pyrido[1,2a]pyrimidin-4-one (4) in ethanol at room temperature for $3 \mathrm{~h}$ giving a product which has been characterized as 2-(1-(4-oxo4H-pyrido[1,2-a]pyrimidin-3-yl)ethylidene)hydrazine carbothioamide (5a), whose structure has been assigned in the basis of its spectral data. Similar reaction of $\mathbf{4 b}$ (i.e., $\mathbf{4}, \mathrm{X}=\mathrm{Br}$ ) with thiosemicarbazide resulted in the formation of $\mathbf{5 b}$ (i.e., $\mathbf{5}$, $\mathrm{X}=\mathrm{Br}$ ), whose structure has been established on the basis of its spectral data.

A solution of compound $\mathbf{5}$ (i.e., $\mathbf{5}, \mathrm{X}=\mathrm{H}$ ) acetic acid, sodium acetate and add phenacyl bromide derivative reflux for $4 \mathrm{~h}$ gave a product which has been characterized as 3-(12-(4-(4-chloro-phenyl)thiazol-2-yl)hydrazono)ethyl)-4Hpyrido[1,2-a]pyrimidin-4one (6) (i.e., 6, X = H). Similar reaction of compound $\mathbf{5}$ (i.e., $\mathbf{5}, \mathrm{X}=\mathrm{Br}$ ) with acetic acid, sodium acetate and add 1-bromo-3-(4-chlorophenyl)propane-2-one derivative gave $\mathbf{6 b}$ (i.e., $\mathbf{6}, \mathrm{X}=\mathrm{Br}$ ), whose structure has been established on the basis of its spectral data.

A solution of compound $\mathbf{5}$ (i.e., 5, X=H) ethanol, dimethylacetylene-dicarboxylate (DMAD) reflux for $3 \mathrm{~h}$ gave methyl4-oxo-2-(2-(1-(4-oxo-4H-pyrido[1,2-a]pyrimidin-3-yl)ethylidene)hydrazinyl)-4,5-dihydrothiazole-5-carboxylate which has been characterized 7 (i.e., 7, $\mathrm{X}=\mathrm{H}$ ) on the basis of its spectral data. Similar reaction of compound $\mathbf{5 b}$ (i.e., $\mathbf{5}$, $\mathrm{X}=\mathrm{Br}$ ) with acetic acid, sodium acetate and add phenacyl bromide derivative gave compound $\mathbf{7 b}$ (i.e., 7, $\mathrm{X}=\mathrm{Br}$ ), whose structure has been established on the basis of its spectral data.

A solution of compound 5 (i.e., 5, $\mathrm{X}=\mathrm{H}$ ) 1,4-dioxane, chloroacetic acid a few drops of triethylamine reflux for $5 \mathrm{~h}$ gave 2-2-(4-oxo-4H-pyrido[1,2-a]pyrimidin-3-yl)ethylidene)hydrazinyl)thaizol-4(5H)-4-one (8) (i.e., 8, X=H) which has been characterized on the basis of its spectral data. similar reaction of $\mathbf{5 b}$ (i.e., $\mathbf{5}, \mathrm{X}=\mathrm{Br}$ ) with acetic acid, sodium acetate and add phenacyl bromide derivative gave the product $\mathbf{8 b}$ (i.e., $\mathbf{8}, \mathrm{X}=\mathrm{Br}$ ), whose structure has been established on the basis of its spectral data.

\section{Conclusion}

In conclusion, a new pyridopyrimidine derivatives from 2-aminopyridine by simple and convenient method are synthesized. These compounds are unknown synthones and may be used for the synthesis of various heterocyclic systems by functional group interconversion. The noteworthy advantages of the reaction conditions includes multi-operational utility.

\section{ACKNOWLEDGEMENTS}

The authors are thankful to the authorities of Jawaharlal Nehru Technological University, Hyderabad, India for providing laboratory facilities and financial support to one of them (PV).<smiles>[X]c1ccc(N)nc1</smiles><smiles>[X]c1ccc2ncc(/C(C)=N/NC(N)=S)c(=O)n2c1</smiles>

Scheme-I: Synthesis of 2-(1-(4-oxo-4H-pyrido[1,2-a]pyrimidin-3-yl)-ethylidene)hydrazine carbothioamide<smiles>[X]c1ccc(N([Tl])C=C(C(C)=O)C(=O)OCC)nc1</smiles><smiles></smiles>

(3) $\mathrm{H}$

Scheme-II: Plausible mechanism of cyclization of compound 4 


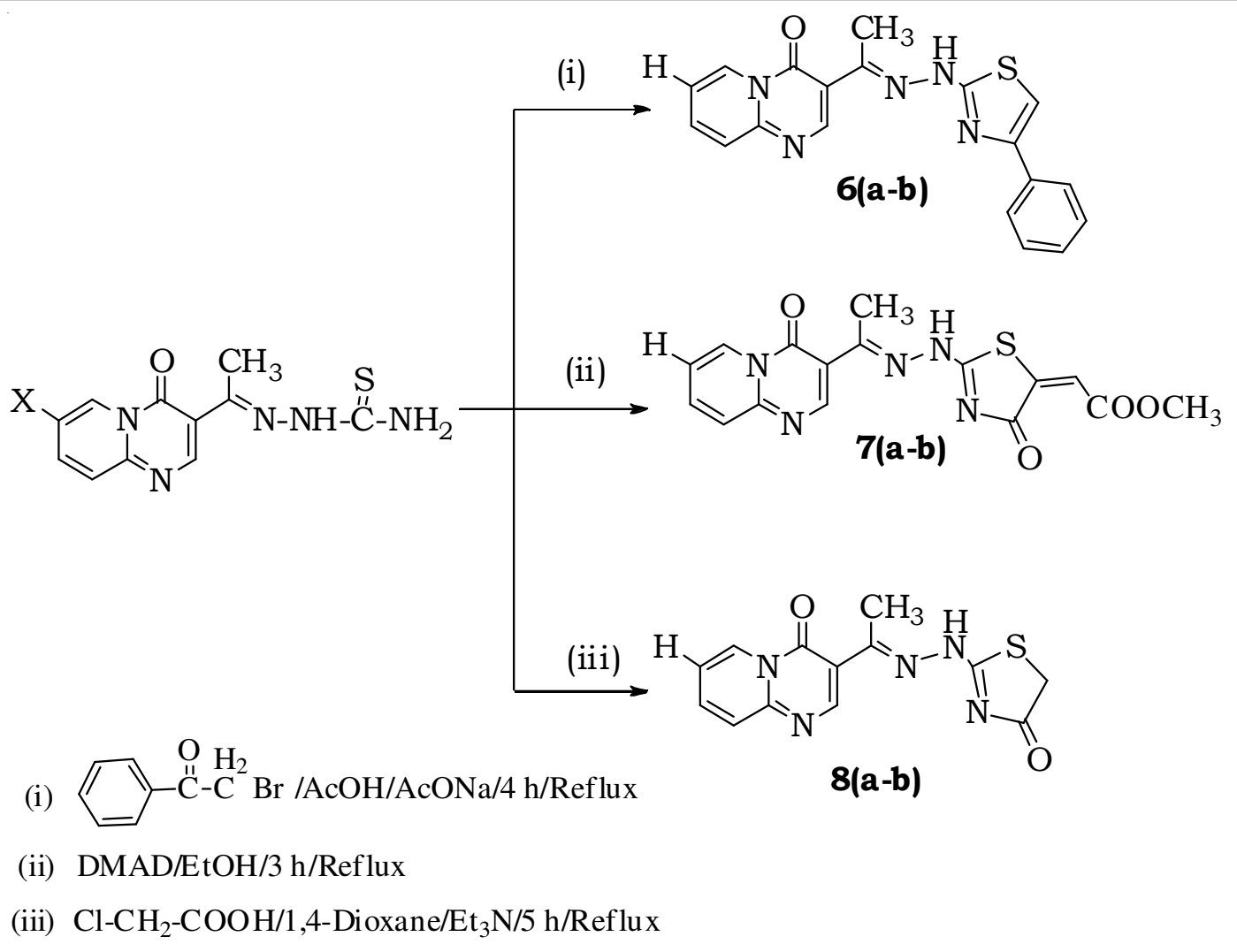

Scheme-III

\section{REFERENCES}

1. M.C. Pirrung, S.V. Pansare, K.D. Sarma, K.A. Keith and E.R. Kern, J. Med. Chem., 48, 3045 (2005);

https://doi.org/10.1021/jm049147h

2. W.X. Hu, W. Zhou, C.N. Xia and X. Wen, Bioorg. Med. Chem. Lett., 16, 2213 (2006);

https://doi.org/10.1016/j.bmcl.2006.01.048.

3. A. Kolocouris, K. Dimas, C. Pannecouque, M. Witvrouw, G.B. Foscolos, G. Stamatiou, G. Fytas, G. Zoidis, N. Kolocouris, G. Andrei, R. Snoeck and E. De Clercq, Bioorg. Med. Chem. Lett., 12, 723 (2002); https://doi.org/10.1016/S0960-894X(01)00838-1.

4. P. Tarasconi, S. Capacchi, G. Pelosi, M. Cornia, R. Albertini, A. Bonati, P.P. Dall Aglio, P. Lunghi and S. Pinelli, Bioorg. Med. Chem., 8, 157 (2000); https://doi.org/10.1016/S0968-0896(99)00260-6.
5. S.A. Mayekar, Indian J. Chem., 47B, 1438 (2008).

6. K. Omar, A. Geronikaki, P. Zoumpoulakis, C. Camoutsis, M. Sokovic, A. Ciric and J. Glamoclija, Bioorg. Med. Chem., 18, 426 (2010); https://doi.org/10.1016/j.bmc.2009.10.041.

7. A. Ignat, T. Lovasz, M. Vasilescu, E. Fischer-Fodor, C.B. Tatomir, C. Cristea, L. Silaghi-Dumitrescu and V. Zaharia, Arch. Pharm. Chem. Life Sci., 345, 574 (2012); https://doi.org/10.1002/ardp.201100355.

8. S. Gomha and K.D. Khalil, Molecules, 17, 9335 (2012); https://doi.org/10.3390/molecules17089335.

9. L.L. Awad, M.Abdel-Rahman, M. Zakaria and E.H. El-Ashy Alexandria, J. Pharm. Sci., 3, 119 (1989); Chem. Abstr., 114, 42661u (1991).

10. B. Kalluraya and G. Rai, Synth. Commun., 34, 4055 (2004); https://doi.org/10.1081/SCC-200036580. 